$5 \quad$ Negar Akbari*, Dylan Jones, Richard Treloar

\title{
A Cross-European Efficiency Assessment of Offshore Wind Farms: a DEA Approach
}

6 Centre for Operational Research and Logistics (CORL), School of Mathematics and Physics,

7 University of Portsmouth, Lion Gate Building, Lion Terrace, Portsmouth, PO1 3HF, United

8 Kingdom

9

10

\section{Abstract}

Offshore wind energy is recognized as an important source of renewable energy and has experienced a rapid growth in recent years especially in north-western European countries. In this paper the efficiency of 71 offshore wind farms across five north-western European countries is assessed using the Data Envelopment Analysis (DEA) Method. The number of turbines, cost, distance to shore, and area of the wind farms are selected as the inputs and the connectivity to population centres, the produced electricity and the water depth are considered as the outputs. The results show that the average CCR efficiency score of all offshore wind farms considered in this study is $87 \%$, and the relative median efficiency of offshore wind farms in different countries is not statistically different. This study offers a practical and holistic performance assessment to the offshore wind stakeholders and policy makers via including economic, environmental, technical and social inputs and outputs in the analysis.

\section{Key words}

Renewable Energy; Decision Making; Offshore Wind Farms; Data Envelopment Analysis; Efficiency Assessment 
The offshore wind industry has experienced remarkable growth in the past two decades, and has become a mainstream technology in many European countries while also expanding in Asia and North America. Countries such as the United Kingdom, Germany, Belgium, Denmark and the Netherlands are at the forefront of developing offshore wind farms, and by the end of 2018, Europe had a total installed offshore wind capacity of 18.4 GW [1]. Different factors including the accessibility from coastlines, lower visual impact, higher wind speed and the possibility to place large wind turbines to gain economies of scale and efficiency have increased the attractiveness of this type of renewable energy [2] . However, issues related to intermittency and unpredictability of the wind, harsh sea and weather conditions, and complex logistics are among the challenges faced by the industry[3]. In order to ensure that maximal efficiency gains are achieved in the countries in which offshore wind energy is being deployed in an industrial scale, the Data Envelopment Analysis method (DEA) is proposed in this paper. This analysis can provide a better understanding of the current state of the industry and provide a best practice frontier of the operational and inconstruction wind farms across north-west Europe considering social, technical, economic and environmental factors.

In the seminal work of Charnes et al. [4] , DEA is introduced as a method for measuring the efficiency of a set of decision making units. The initial idea of DEA can be traced back in the economics literature through defining a simple measure for efficiency that could account for multiple inputs and outputs within the context of technical, allocative and productive efficiency [5]. Based on a survey by liu et al. [6], DEA has been used in traditional industries such as agriculture, manufacturing and health care, as well as modern industries such as software and e-business, and is particularly an accepted approach for efficiency evaluation and benchmarking in the energy and environment sector [7]. Within the context of benchmarking, DEA could be considered as a multiple criteria decision analysis method, however its main goal is to evaluate the relative efficiency of a set of comparable entities (decision making units) rather than choosing a specific alternative as it is usually the case in decision analysis methods [8]. Thus, DEA can be regarded as a descriptive analytical method, although an analysis of its results can lead to some prescriptive recommendations.

The contributions of this study are threefold including i) providing a benchmark study of the current efficiency status of the European offshore wind industry ii) determining the factors 
affecting the efficiency of offshore wind farms and iii) Providing a statistical analysis of the difference in efficiency scores of the countries by grouping the windfarms into three categories of UK, Germany-Denmark and Netherlands-Belgium. The remainder of this paper is as follows: In Section 2, the literature review is conducted and the gaps in the literature are highlighted. In Section 3, a DEA analysis is presented including a discussion of the results and the statistical and sensitivity analysis, and in Section 4 the conclusions and future research avenues are discussed.

\section{Literature review}

Data Envelopment Analysis is a non-parametric method that evaluates the relative efficiency of a set of Decision Making Units (DMUs) by a specific mathematical programming model. In contrast to parametric methods such as Stochastic Frontier Analysis (SFA), for which an explicit functional form for the technology and frequency for the distribution of the inefficiency term is imposed; in the DEA method no prior assumption on the underlying functional relationship between inputs and outputs is required [9]. The DEA method divides the DMUs into efficient and inefficient subsets, where efficient units receive value of 1 and inefficient DMUs receive values less than 1. Therefore, the method allows for the identification of DMUs exhibiting best practice and the formation of an efficient frontier [10].

Two main varieties of DEA are developed in the literature, the CCR (Charnes, Cooper and Rhodes) model, which is based on the hypotheses of constant returns to scale (CRS) and it measures the overall efficiency; and BCC (Banker, Charnes and Cooper) model, which is based on the hypotheses of variable returns to scale (VRS) measuring the pure technical efficiency. The scale efficiency is estimated through the ratio of overall efficiency score to pure efficiency score. The CRS model has been applied for this analysis since constant return to scale is assumed.

\subsection{Applications of DEA in the renewable energy sector}

In this section, some of the applications of DEA in the onshore wind, offshore wind and wave sector are presented in order to review the inputs and outputs that have been used in the literature. Ederer [10] has applied the DEA methodology for assessing the efficiency of 22 offshore wind farms in Europe in terms of capital cost efficiency and operating cost efficiency. For the assessment of capital cost efficiency, the capital cost is considered as the input and installed capacity, distance to shore and water depth as the outputs. For the 
operating cost efficiency, the operating cost is the input and the installed capacity, distance to operating port, energy performance and availability are the outputs. Using both BCC and CCR methods, the scale efficiency of the wind farms is determined. The learning-by-doing rate for capital cost efficiency shows that the efficiency has increased with accumulated experience. Furthermore, the Tobit regression applied in their study shows increasing capital cost efficiency as a function of time, and a decreasing operating cost efficiency as a function of operating year.

Saglam [11]uses a two stage DEA model for efficiency assessment of onshore wind energy in 39 states in the United States. In the first stage of the model, a BCC and CCR model is developed that takes the installed wind capacity, number of wind turbines, total project investment and annual land lease payment as inputs; and the net generation, percentage of instate energy production, number of US homes powered, wind industry employment, annual water savings and $\mathrm{CO} 2$ emissions avoided as the outputs. Sensitivity analysis is also conducted for assessing the robustness of the model and shows that electricity generation related output variables and capital and technology related inputs are critical factors affecting the efficiency scores. Furthermore, Tobit regression models investigate the effectiveness of the invested money and the productivity of the wind turbine technologies and shows that early installed wind power was more expensive and less productive than the current installed wind power.

Wu et al. [12] apply a two stage DEA for efficiency assessment of 42 onshore wind farms in China. They use the installed capacity, electricity consumption and wind power density as the inputs and the generated electricity and availability as the outputs. The Tobit regression analysis is used to assess the relationship score of the CCR model with the uncontrollable variables (age, wind curtailment rate, dummy variable for ownership effect). The regression findings suggest that age and wind curtailment rate have a negative effect on the productive efficiency while the ownership effect does not have a significant impact.

Iglesias et al. [13] use DEA and SFA to measure the efficiency of 57 Spanish onshore wind farms using the capital, labour and fuel (wind) as inputs and the electrical energy produced by the wind farm. Their result show that the DEA BCC model has the highest efficiency score, followed by SFA and CCR model. High average technical efficiency (exceeding $75 \%$ ) is reported and they show correlation of the average size of the standard wind turbine with the year of installation. 
Halkos and Tzeremes [14], apply a bootstrapped DEA model for evaluation of financial performance of 78 firms operating in the Greek renewable energy sector and concluded that firms operating in the wind power energy sector had higher financial efficiency compared to firms in the hydroelectric power sector. They have considered debt/equity ratio, current ratio and asset turnover ratio as input variables and return on equity, return on asset gross profit margin and operating profit margin as output variables. San Cristobal [15] uses DEA to assess the efficiency of thirteen different renewable energy technologies related to wind power, hydroelectric, solar, biomass and biofuel using the investment ratio, implement period and operating and maintenance cost as inputs and power generation, operating hours, useful life and $\mathrm{CO}_{2}$ avoided as outputs. Kim et al. [16] apply DEA to assess the investment efficiency of photovoltaic, onshore wind power and fuel cells in South Korea considering policy objectives of public investment, technological development and wider dissemination of new and renewable energy in South Korea. Based on their analysis, wind power turns out to be the most efficient technology from a government investment perspective. Stallard et al. [17] use the DEA method to compare the efficiency of a set of three hypothetical and one prototype wave energy conversion technologies at eight distinct UK wave climates considering 7 inputs and one output. It is suggested that the DEA provides straight forward means of selecting the technology, which maximises aggregate electricity generation with minimum inputs and without recourse to conducting a cost study for each site.

DEA is also used for the analysis of energy efficiency on country level. DEA has been applied to assess the efficiency of BRIC countries and Mediterranean countries respectively, both using energy consumption, labor force and gross fixed capital formation as inputs and the GDP as an output by [18] and [19]. Location optimization of wind plants in Iran has been conducted using fuzzy DEA in which in addition to wind speed, local and social criteria such as population of the region, geological and geographical consideration and cost have been considered by [20].

It is noted that, whilst the above papers conducted successful and informative DEA analyses, they concentrate on onshore rather than offshore wind farms in their assessment of wind energy. Furthermore, there is often, but not exclusively, an emphasis on financial efficiency factors rather than technical/ logistical factors. This paper presents an efficiency analysis for a offshore wind farms across five European considering social, technical, environmental and 
153 economic factors and fills the gap in the current literature in the application of the DEA 154 method to the offshore wind energy sector.

\section{A DEA analysis of the offshore wind industry}

156 DEA was extended by Charnes et al. [4] and Banker et al. [21] to propose the Charnes157 Cooper-Rhodes model (CCR) with constant returns to scale (CRS) and Banker-Charnes158 Cooper (BCC) with variable returns to scale (VRS). The CCR model is formulated below by 159 (1)-(3) assuming that there are $j$ DMUs to be evaluated $(j=1, \ldots, n), r$ is the output index $160(r=1, \ldots, s) ; i$ is the input index $(i=1, \ldots, m) ; x_{i j}$ the value of the $i_{t h}$ input of the $j_{t h}$ 161 DMU; and $y_{r j}$ the value of the $r_{t h}$ output; $u_{r}$ is the weight assigned by the DEA model to 162 the $r_{t h}$ output; $v_{i}$ is the weight assigned by the DEA model the $i_{t h}$ input; and $\theta$ the relative 163 efficiency of $\mathrm{DMU}_{\mathrm{j}}$ in the following manner:

$$
\operatorname{Max} \theta=\sum_{r=1}^{s} u_{r} y_{r j}
$$

164 s.t.

$$
\begin{gathered}
\sum_{r=1}^{s} u_{r} y_{r j}-\sum_{i=1}^{m} v_{i} x_{i j} \leq 0 \\
\sum_{i=1}^{m} v_{i} x_{i j}=1 \\
u_{r}, v_{i} \geq 0 \quad \forall r, i
\end{gathered}
$$

165 Although the DEA methodology has its roots in economics and production theory, it has been used extensively within the realm of operations management for benchmarking the

167 performance of decision making units. In this domain, instead of forming a production 168 frontier, the efficient DMUs form a best practice frontier [18]. In the remainder of this section 169 the rationalization behind the selection of the inputs and outputs of the DEA model developed 170 in this paper is presented. 


\subsection{Selection of Inputs and outputs}

172 For the classification of inputs and outputs, it is suggested that if the underlying problem represents a form of production process, then the selected inputs are usually the resources used or required, and the outputs are the outcome of the process. However, if the problem refers to a benchmarking problem, then the inputs may be selected based on the assumption of "the less the better" and the outputs may be selected based on the assumption of "the more the better" [22]. For this analysis, DEA is employed as a multiple criteria decision making tool where the DMUs are alternatives and the inputs and outputs are two sets of performance criteria where the input is to be minimized and the output to be maximized [22]. The problem of efficiency assessment of offshore wind farms can therefore be classified as a benchmarking problem as it does not only consider the production of electricity given a number of resources, but it assesses the offshore wind farms including other factors including the social impact, cost, and the connectivity to population centres. While it can never be guaranteed that the chosen set of inputs and outputs that perfectly reflect the process under study are included in the DEA analysis, every attempt should be made to insure that the selected measures reflect the process under study in as detailed a way as possible. In the next section, a description and justification for selection is provided for each of the inputs and outputs used in this study. The main categories of the inputs and outputs are defined as: i) the Economic criteria including the cost, and the amount of produced electricity, ii) the Technical criteria including the number of turbines, and water depth, iii) the Social criteria including the distance to shore and connectivity to population centres and iv) the Environmental criteria including the area of the offshore wind farm. A detailed description of all the inputs and output is provided in Sections 3.1.1 and 3.1.2.

\subsubsection{Inputs}

The description of the four inputs including the number of turbines, cost, distance to shore and the area of the wind farm is provided below:

1) Number of turbines: the number of turbines has been selected as an input since it corresponds to the capacity of the wind farm and also affects the construction, operation and maintenance of the wind farm. The number of turbines has a direct impact on the cost of the wind farm, particularly the operation and maintenance cost, and also the amount of area that the wind farm occupies in the sea, which is a factor which affects its 
environmental impact. Therefore, this parameter has been chosen as an input since the best output performance from as few a number of turbines is desirable.

2) Cost: amongst the most important parameters with which offshore wind projects are assessed is the cost of the project. Distance from the shore, water depth, the technology used and many other factors can have an impact on the cost of the wind farm. For this analysis the cost component comprises of the construction and operation and maintenance costs (CAPEX plus OPEX) of the wind farm throughout its entire life cycle. Similar to the study by [23] in which the CAPEX value is retrieved from online sources, the authors relied on the publically available sources, and the available literature. The CAPEX data is taken from [24] as the primary source, with [25] used as a secondary source if the wind farm's CAPEX is not found in [24], and the estimated OPEX is taken from [26]. The cost data for the wind farms has been inflation adjusted based on their year of commissioning up to the end of year 2018 [27]. The cost parameter has been chosen as an input since a best output performance at a lower cost is desirable.

3) Distance to shore: the distance to shore is included as it relates to the sea scape, landscape and visual impact of the wind farm. While offshore wind farms are subjected to the NIMBY effect (not in my back yard) less than that of onshore wind turbines, there are still issues associated with their visual impact, and the impact they could have on the local industries of the region such as tourism. An example of this case is the rejected Navitus Bay wind farm that was planned to be built in the South of England. Amongst the important reasons for the rejection of this project was that the scale and location of the project would affect areas of outstanding beauty over a widespread area of coastline. The wind farm would be visible from vantage points along a $30 \mathrm{~km}$ section of the eastern edge of the World Heritage site with the closest point lying on the shore approximately $15 \mathrm{~km}$ from the edge of the wind turbine layout [28]. It is therefore desired that the wind farms are built at a distance from the shore to lower their negative social impact, which is better. Certainly this can lead to a trade-off between the cost and social impact inputs that forms part of the intrinsic reasoning of the DEA analysis. Table 1 presents the figures used for calculating the impact of the distance to shore of the windfarms.

4) Offshore wind farm area: this input is related to the marine footprint of the offshore wind farm. Although offshore wind farms are under less space restriction compared to on-land wind farms, they are still in competition with other sea-users in terms of the space that can be allocated to them. However, some studies suggest the positive effect of the construction of offshore wind farms for the marine environment. This is due to the fact 

that the construction of the offshore wind farms have contributed to the recovery of vulnerable species due to those areas being closed to beam trawl fisheries [29]. However, the overall impact of the offshore wind farm area is such that it can be considered as an input, since best output performance from a smaller area is desirable for the wind farms. This is particularly true of the crowded maritime spaces in European waters where the wind farms considered in this study are located. Hence, in this study the negative impacts of the offshore wind farm area have been considered and this parameter is used as an input (i.e. the lower the better). The area that the offshore wind occupies in the sea is important due to the following reasons [30]:

- The larger the area, the larger the marine footprint which may lead to marine life interruptions, fishing industry prohibitions, and leisure industry limitations.

- The larger area of the wind farms could lead to marine transportation disruptions, since the offshore wind industry competes with other industries such as container shipping, bulk shipping, defence vessel movements, and passenger ferry line alterations.

- The larger area of wind farm may be due to greater number of turbines employed or larger spacing between turbines which could lead to higher installation, O\&M and decommissioning costs. Therefore, it may be desirable to increase the capacity of the wind turbines rather than the number of turbines.

\begin{tabular}{|c|c|}
\hline $\begin{array}{c}\text { Distance from shore } \\
(\mathrm{km})\end{array}$ & Impact score \\
\hline $1-10$ & 5 \\
\hline $10-20$ & 3 \\
\hline $20-30$ & 2 \\
\hline $30-40$ & 1 \\
\hline \multicolumn{2}{|c|}{ Distance $>40$} \\
\hline \multicolumn{2}{|c|}{ Table 1: distance from shore impact score } \\
\hline
\end{tabular}




\subsubsection{Outputs}

Three outputs, namely the connectivity to population centres, produced electricity and the water depth have been selected for the DEA model as described below:

1) Connectivity to population centres: the connectivity and proximity of the wind farm to the population centres is an important parameter since this will allow a lower strain in terms of grid accessibility and logistics. This output is calculated as the distance of the wind farm to nearest medium sized city within $250 \mathrm{~km}$ with a population density above 1000 person $/ \mathrm{km}^{2}$. It is desired that the connectivity is maximised and therefore this parameter has been inverted and used as an output of the model.

2) Electricity produced: this parameter measures the amount of estimated theoretical annual electricity produced by the wind farm using the average wind speed data for each location. Based on the Betz momentum theory the amount of mechanical energy that can be extracted from a free stream airflow by an energy convertor is limited to around 59\% of $E$ using the equation below:

$$
E=\left(\frac{1}{2}\right) A \rho v^{3} t
$$

Where $A$ designates the swept area of the rotor $\left(A=\pi r^{2}\right), \rho$ represents the air density, $v$ is the average wind speed, and $t$ is the time.

Since an important goal of the wind farm is to maximize its electricity production, this parameter is chosen as an output.

3) Water depth: In order to take better advantage of energy resources at sea, the offshore wind industry is developing wind turbine concepts for deployments in deeper waters. Some offshore wind projects are now planned for instalment in water depths up to $50 \mathrm{~m}$, which require a shift from the monopile foundation (which are used in about $96 \%$ of the presently commissioned wind farms) to novel foundation types such as floating structures [31]. The ability to produce energy efficiently at greater water depths is seen as a positive development and this parameter is therefore used in this analysis as an output.

The suitable number of inputs and outputs with relation to the number of DMUs is amongst the debated topics within the DEA literature. Banker et al. [21] suggest that the number of DMUs should be at least three times the number of inputs and outputs while [32] suggest that the number of DMUs should be two times greater the combined number of inputs and outputs, however this rule may not be imperative [22]. They point out that while in statistical 
regression analysis, the sample size can be a critical issue as it tries to estimate the average behaviour of a set of DMUs, DEA focuses on individual DMU performance. In that sense the number of DMUs under evaluation may be immaterial. For this analysis a combined number of 7 inputs and outputs and 71 DMUs are considered, which comfortably meets the suggested rules of [21] and [32].

\subsection{Data description}

It is suggested that for the DEA analysis a mixture of raw data (e.g. revenue, number of employees) and percentile/ratio data (e.g. returns on investment, profit per employee) can be used simultaneously [22]. The type of data used for this DEA analysis is raw data and none of the inputs or outputs have an equal value across all DMUs. The data related to the inputs and outputs has been retrieved from the literature [33], [10], and publically available data sources including online resources [24],[25]. The sample consists of 71 operational and in construction offshore wind farms and excludes any demonstration wind farms. The statistical description of the input and output data used for this analysis is described below in Table 2 .

\begin{tabular}{|c|c|c|c|c|c|}
\hline \multicolumn{2}{|c|}{ Parameters } & Median & Min & $\operatorname{Max}$ & Standard deviation \\
\hline$x_{1}$ & $\begin{array}{l}\text { Number of } \\
\text { turbines }\end{array}$ & 60 & 6 & 175 & 37 \\
\hline$x_{2}$ & $\begin{array}{c}\operatorname{Cost}(£ \\
\text { million/MW) }\end{array}$ & 5.96 & 2.77 & 11.44 & 1.79 \\
\hline$x_{3}$ & $\begin{array}{c}\text { Distance to shore } \\
(1-5)\end{array}$ & 3.00 & 1 & 5 & 1.44 \\
\hline$x_{4}$ & $\operatorname{Area}\left(\mathrm{km}^{2}\right)$ & 33.00 & 2 & 407 & 59.55 \\
\hline$y_{1}$ & Connectivity $(\mathrm{km})$ & 80.25 & 6.45 & 250 & 66.77 \\
\hline$y_{2}$ & $\begin{array}{c}\text { Generated } \\
\text { electricity }(\mathrm{GWh})\end{array}$ & 977.67 & 48.12 & 5289 & 943.036 \\
\hline$y_{3}$ & Water Depth(m) & 19 & 2.5 & 42.5 & 10.006 \\
\hline
\end{tabular}


303 Tables 3 shows the result of the CCR DEA analysis of 71 offshore wind farms across five 304 countries: United Kingdom, Germany, Denmark, Netherlands and Belgium. The table 305 presents the efficiency scores for the wind farms and the reference set, i.e. the set of efficient units from which the inefficiency of non-efficient units is determined.

\begin{tabular}{|c|c|c|c|}
\hline & Wind Farms & Efficiency & Ref Set \\
\hline 1 & Scroby Sands & 0.84 & $3 ; 4 ; 31 ; 44 ;$ \\
\hline 2 & North Hoyle & 0.89 & $3 ; 4 ; 31 ; 58$ \\
\hline 3 & Kentish Flats & 1.00 & 3 \\
\hline 4 & Burbo Bank & 1.00 & 4 \\
\hline 5 & Burbo Bank Extension & 1.00 & 5 \\
\hline 6 & Beatrice & 0.92 & $12 ; 44 ; 58$ \\
\hline 7 & Hornsea project 1 & 1.00 & 7 \\
\hline 8 & East Anglia 1 & 1.00 & 8 \\
\hline 9 & Dudgeon & 0.78 & 4;5;7;44; \\
\hline 10 & Rampion & 0.83 & $3 ; 42 ; 44 ; 58 ;$ \\
\hline 11 & Galloper & 0.90 & $5 ; 44 ; 55 ;$ \\
\hline 12 & Walney Extension & 1.00 & 12 \\
\hline 13 & Walney Phase 1 & 0.79 & $44 ; 47 ; 49 ; 58 ; 66 ;$ \\
\hline 14 & Walney Phase 2 & 0.79 & $4 ; 31 ; 44 ; 49 ; 58$ \\
\hline 15 & Race bank & 1.00 & 15 \\
\hline 16 & Lincs & 0.64 & 4;44;62;66; \\
\hline 17 & London Array & 0.99 & $3 ; 7 ; 62 ;$ \\
\hline 18 & Lynn & 0.87 & $4 ; 31 ; 44 ; 49 ; 66$ \\
\hline 19 & Teeside & 0.75 & $44 ; 48 ; 49 ; 66$ \\
\hline 20 & Thanet & 0.74 & $3 ; 4 ; 31 ; 44 ; 58$ \\
\hline 21 & Sheringham Shoal & 0.76 & $31 ; 44 ; 58 ; 66$ \\
\hline 22 & Rhyl Flats & 0.75 & $4 ; 31 ; 44 ; 49 ;$ \\
\hline 23 & Robin Rigg & 0.62 & $3 ; 12 ; 44 ; 62 ;$ \\
\hline 24 & Ormonde & 0.95 & 44;47;49;58;66; \\
\hline 25 & Westermost rough & 0.94 & $4 ; 5 ; 44 ; 49 ; 66 ;$ \\
\hline 26 & West of duddon sands & 0.79 & $3 ; 4 ; 44 ; 62$ \\
\hline 27 & Gwynt y Mor & 0.95 & $3 ; 12 ; 44 ; 62 ;$ \\
\hline 28 & Gunfleet Sands & 0.65 & $4 ; 44 ; 62 ; 66 ;$ \\
\hline 29 & Greater Gabbard & 0.74 & $3 ; 4 ; 7 ; 12 ; 62 ;$ \\
\hline 30 & Humber Gateway & 0.74 & $4 ; 44 ; 62 ; 66$ \\
\hline 31 & Barrow & 1.00 & 31 \\
\hline 32 & Amrumbank West & 0.85 & $44 ; 48 ; 54 ; 66$ \\
\hline 33 & Bard Offshore 1 & 1.00 & 33 \\
\hline
\end{tabular}




\begin{tabular}{|c|c|c|c|}
\hline 34 & Butendiek & 0.80 & $44 ; 54 ; 62 ; 66$ \\
\hline 35 & EN BW Baltic 1 & 0.76 & $44 ; 47 ; 49 ; 58 ; 66$ \\
\hline 36 & EN BW Baltic 2 & 0.92 & $44 ; 47 ; 49 ; 66$ \\
\hline 37 & Dantysk & 0.75 & $8 ; 44 ; 47 ; 48 ; 62 ; 66$; \\
\hline 38 & Global Tech 1 & 1.00 & 38 \\
\hline 39 & Riffgat & 0.93 & $48 ; 49 ; 54 ; 66$ \\
\hline 40 & Sand bank & 0.81 & $44 ; 48 ; 62 ; 66$ \\
\hline 41 & Trianel windpark Borkum & 1.00 & 41 \\
\hline 42 & Arkona & 1.00 & 42 \\
\hline 43 & Borkum Riffgrunde 1 & 0.87 & $44 ; 47 ; 48 ; 49 ; 66$ \\
\hline 44 & Borkum Riffgrund 2 & 1.00 & 44 \\
\hline 45 & Merkur & 0.90 & 7;44;47;50;66;71; \\
\hline 46 & Nordergrunde & 0.81 & $5 ; 44 ; 55 ; 66 ;$ \\
\hline 47 & Wikinger & 1.00 & 47 \\
\hline 48 & Veja mate & 1.00 & 48 \\
\hline 49 & Alpha Ventus & 1.00 & 49 \\
\hline 50 & Nordsee One & 1.00 & 50 \\
\hline 51 & Meerwind sud/ost & 0.82 & $44 ; 47 ; 48 ; 49 ; 66$ \\
\hline 52 & Belwind & 0.79 & 44;47;49;66; \\
\hline 53 & Nobelwind & 0.87 & $44 ; 47 ; 49 ; 66$ \\
\hline 54 & Northwind & 1.00 & 54 \\
\hline 55 & Thornton Bank 1 & 1.00 & 55 \\
\hline 56 & Thonton Bank 2 & 0.87 & $4 ; 5 ; 44 ; 49 ;$ \\
\hline 57 & Thornton Bank 3 & 0.81 & $44 ; 49 ; 55 ; 66 ;$ \\
\hline 58 & Rentel & 1.00 & 58 \\
\hline 59 & Norther & 0.84 & $12 ; 31 ; 44 ; 58$ \\
\hline 60 & Egmond aan Zee & 0.87 & $4 ; 31 ; 49 ; 58 ; 66 ;$ \\
\hline 61 & Eneco Luchterduinen & 0.92 & $31 ; 49 ; 58 ; 66$ \\
\hline 62 & Gemini & 1.00 & 62 \\
\hline 63 & Prinses Amalia & 0.84 & 49;54;66; \\
\hline 64 & Westermeerwind & 0.73 & $3 ; 4 ; 7 ; 62$ \\
\hline 65 & Anholt & 0.71 & $3 ; 7 ; 12 ; 62$ \\
\hline 66 & Middlegrunden & 1.00 & 66 \\
\hline 67 & Rodsand 2 & 0.91 & $4 ; 7 ; 44 ; 66 ; 69 ;$ \\
\hline 68 & Horns Rev 3 & 0.96 & $3 ; 7 ; 12 ; 44 ;$ \\
\hline 69 & Horns Rev 1 & 1.00 & 69 \\
\hline 70 & Nysted & 0.47 & $4 ; 31 ; 44 ; 66 ;$ \\
\hline 71 & Horns Rev2 & 1.00 & 71 \\
\hline
\end{tabular}

Table 3: Efficiency score of offshore wind farms

308 Table 4 and Figure 1 show the dominant wind farms with the highest frequency in the 309 reference set. For instance, the first row in Table 4 shows that wind farm (Kentish Flat) 310 appears as a reference point for 13 other wind farms (self-references are excluded). On a 311 country level, Germany has the highest total reference set occurrences of any individual 
country. However, each country has a non-negligible number of reference set occurrences, as shown in Table 5. This is perhaps unsurprising given the communality of development of the

314 European wind sector, with key manufacturing and operational stakeholders operating across the region. The shared experiential knowledge is also facilitated by Pan-European research funding and active industry bodies, which hold regular conferences and events. Nevertheless, an individual variance of efficiency can be seen within each country in Table 3. This implies that further sharing of good practice can still take within the sector in order to improve efficiency. There are several offshore wind farms across the region that feature particularly frequently in the reference sets in Table 4 and Figure 1. In this category, the three most dominating wind farms belong to Germany and Denmark, that appear as a reference for multiple, inefficient wind-farms across the whole set of countries with respect to the inputs and outputs considered. However, each country also contains at least one wind farm that dominates at least 10 other wind farms. It is hence recommended that further research takes place into the causal factors that are driving this efficiency at these wind farms on a case-bycase basis. Any factors that are not purely site or age dependent, such as logistical and operational practices, should be highlighted as good practice across the sector. The high level of German and Danish efficiency and high reference values are perhaps representative of the accumulated knowledge via a longer period of "learning through doing", as Denmark was a first mover in the general wind/offshore wind sector. The results of this paper confirm that German and Danish off-shore wind farms can still be looked to for highly efficient examples, although the other North-Western European countries also have their own examples. A further factor driving efficiency could be the location of component manufacturing facilities, a theme that is further discussed in Section 4.

\begin{tabular}{|c|c|c|}
\hline Offshore wind farms & Country & Frequency \\
\hline Kentish Flats & UK & 13 \\
\hline Burbo Bank & UK & 14 \\
\hline Burbo Bank Extension & UK & 5 \\
\hline Hornsea 1 & UK & 8 \\
\hline East Anglia 1 & UK & 2 \\
\hline Walney Extension & UK & 8 \\
\hline Race Bank & UK & 1 \\
\hline Barrow & UK & 12 \\
\hline \multicolumn{2}{|c|}{ Country total } \\
\hline Bard offshore 1 & Germany & 1 \\
\hline Trianel Wind Park & Germany & 1 \\
\hline Arkona & Germany & 2 \\
\hline Global Tech & Germany & 1 \\
\hline
\end{tabular}




\begin{tabular}{|c|c|c|} 
Borkum Riffgrund 2 & Germany & 39 \\
\hline Wikinger & Germany & 11 \\
\hline Veja mate & Germany & 8 \\
\hline Alpha Ventus & Germany & 20 \\
\hline Nordsee One & Germany & 2 \\
\hline \multicolumn{2}{|c|}{ Country total } \\
\hline Thornton Bank 1 & Belgium & $\mathbf{8 5}$ \\
\hline Rentel & Belgium & 10 \\
\hline North Wind & Belgium & 5 \\
\hline \multicolumn{2}{|c|}{ Country total } \\
\hline Cemini Country total & $\mathbf{1 9}$ \\
\hline Middlegrunden & Dhe Netherlands & 14 \\
\hline Horns Rev 2 & Denmark & 14 \\
\hline Horns Rev 1 & Denmark & 2 \\
\hline \multicolumn{2}{|c|}{ Country total } \\
\hline
\end{tabular}

Table 4: reference set frequency of efficient wind farms

336 Figure 1 represents the reference set frequency information graphically corresponding to the frequency column of Table 4.

\section{Reference set frequency of offshore wind farms}

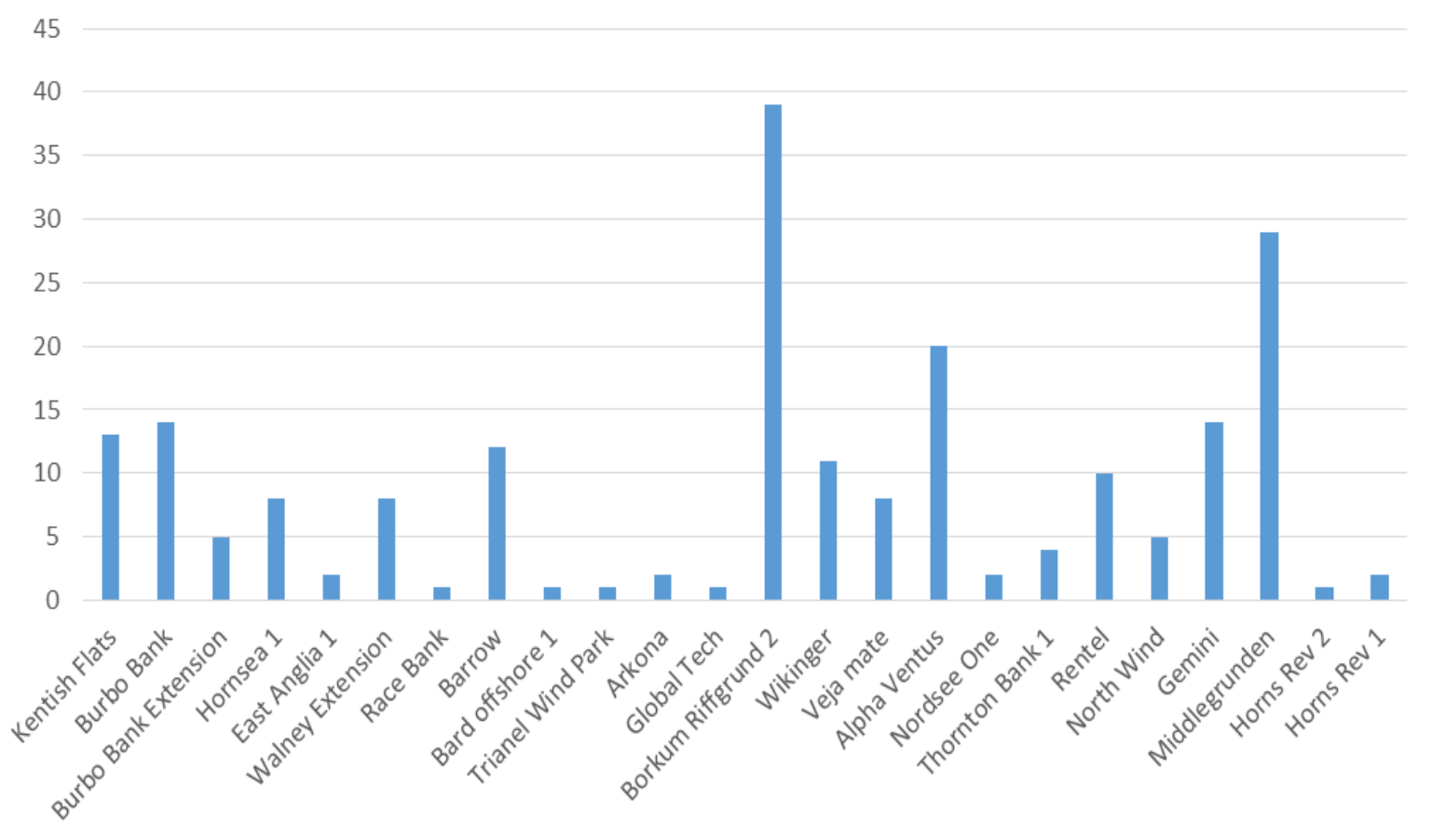

Figure 1: Reference Set frequency of Efficient Wind Farms 


\subsection{Statistical Analysis}

341 It is important to determine whether the median efficiency rating of the wind farms located in different countries is significantly different. In order to conduct the test, three groups are created such that the wind farms located in Netherlands and Belgium form Group 1, Germany and Denmark form Group 2 and the wind farms located in the UK form Group 3. This categorization is done primarily because the number of wind farms in Netherlands, Belgium and Denmark are not large enough to be presented as an individual group for the Kruskal Wallis $\mathrm{H}$ test, hence these countries are grouped together (Belgium-Netherlands and Germany-Denmark) based on the geographical proximity and similarity, to form a group which is suitable for the statistical analysis using non-parametric tests [34]. In order to understand the distribution of the data, the Anderson-Darling test is conducted (Figure 2), which shows that the data is not normally distributed.

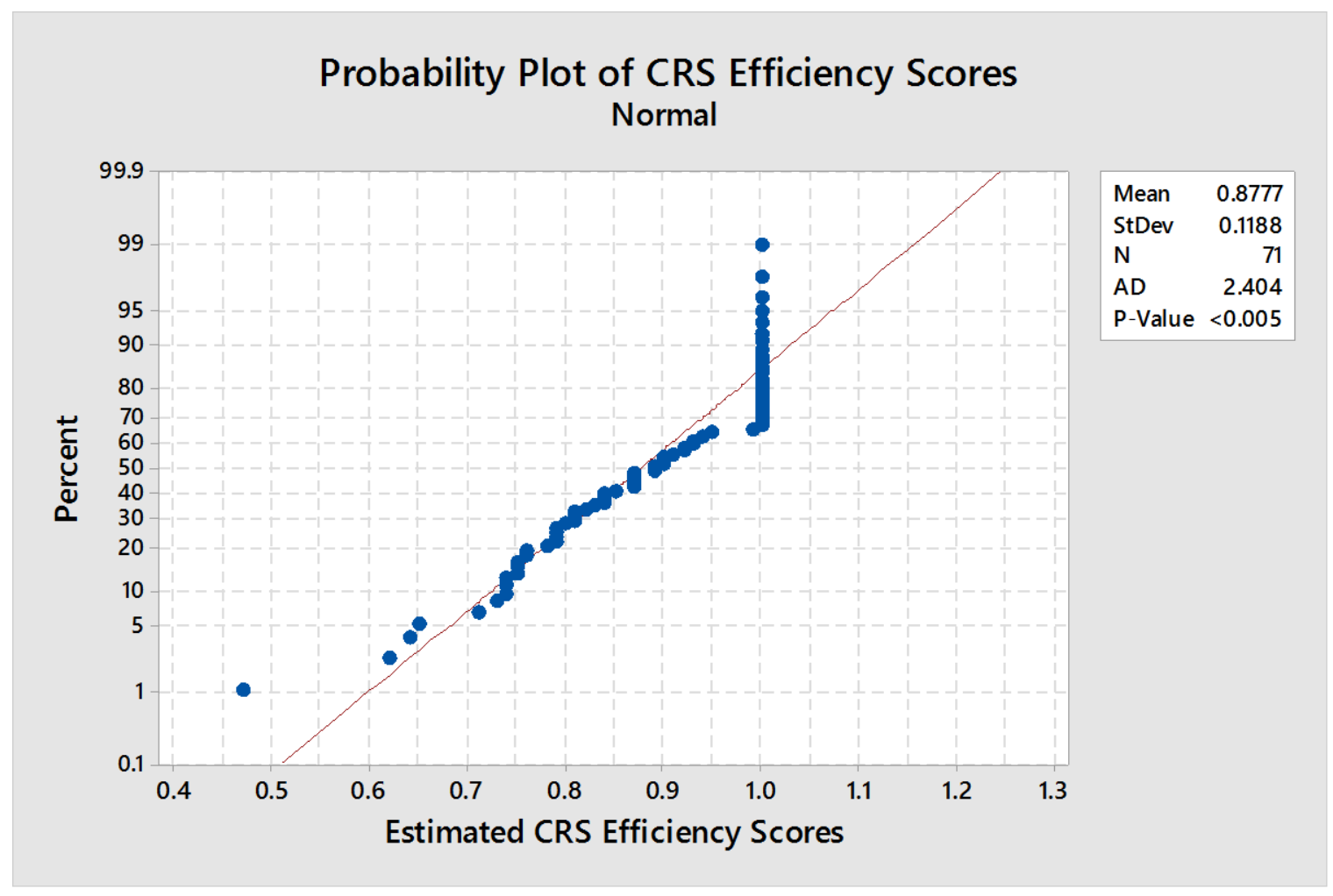

Figure 2: Anderson-Darling normality test of the DEA efficiency scores

The Kruskal-Wallis $\mathrm{H}$ test is conducted to understand if the median efficiency score of the countries are statistically significantly different from one another (i.e. whether the medians of two or more groups differ). The p-value is a probability that measures the evidence against the null hypothesis (i.e. the population medians are all equal) and lower probabilities provide 
stronger evidence against the null hypothesis. The DF (Degree of Freedom) is equal to n-1, where $\mathrm{n}$ represents the number of data groups, and the z-value indicates how the average rank for each group compares to the average rank of all observations, and the higher the absolute value, the further a group's average rank is from the overall average rank.

\begin{tabular}{|c|c|c|c|c|}
\hline Country & $\mathrm{N}$ & Median & $\begin{array}{c}\text { Average } \\
\text { rank }\end{array}$ & $\mathrm{Z}$ \\
\hline Belgium-Netherlands & 13 & 0.87 & 36.4 & 0.08 \\
\hline Germany-Denmark & 27 & 0.93 & 40.6 & 1.47 \\
\hline United Kingdom & 31 & 0.87 & 31.8 & -1.5 \\
\hline Overall & 71 & & 36 & \\
\hline
\end{tabular}

Table 5: Kruskal-Wallis test for efficiency score vs country

The results in Table 5 show that there are no significant differences between the median efficiency score of the three country groups ( $\mathrm{p}$-value=0.257). Therefore, while the median efficiency scores are different, no statistically significant difference can be concluded from the data. This supports the rationale given in Section 3.3 of a connected north-western European offshore wind sector with a diffusion of expertise and knowledge across the region meaning that significant differences of efficiency, when considering the input and output factors of this study, do not appear.

It is noted that the UK offshore wind farms tend to be larger than their continental counterparts, which may be a factor that could give a potential efficiency advantage. However DEA is a relative rather than an absolute efficiency measurement technique, and hence concentrates on the level of output achieved (including electricity generated) per unit of input (including turbines and area). This effect could potentially diminish the role of an absolute measure of the size of the wind farm (e.g in GW) when determining efficiency. One 
possible hypothesis for the median efficiency score of UK being slightly, although not statistically, lower than that of the Germany-Denmark group is found in [35], which gives the location of the component manufacturers for European offshore wind farms as principally located in Germany and Denmark, with consequent longer and more complex supply chains to offshore wind farms in the UK. Although proving this hypothesis is beyond the scope of the DEA analysis in this paper, it is a plausible argument and in line with the DEA results that the longer UK supply chains are causing the slightly lower levels of efficiency at UK offshore wind farms.

\subsection{Sensitivity analysis}

387

A sensitivity analysis is conducted to determine the effects of the elimination of inputs $\left(x_{1}, \ldots, x_{4}\right)$ and outputs $\left(y_{1}, \ldots, y_{3}\right)$ on the DEA efficiency scores. The efficiency scores are reported in Table 6 , where $\mathrm{Y}=$ the variable is included, and $\mathrm{N}=$ the variable is removed from the model. In models 1,2,3 and 4 one of the input variables has been removed, and in models $5,6,7$ one of the output variables has been removed at a time.

\begin{tabular}{|c|c|c|c|c|c|c|c|c|}
\hline & $\begin{array}{c}\text { Original } \\
\text { model }\end{array}$ & Model 1 & Model 2 & Model 3 & Model 4 & Model 5 & Model 6 & Model 7 \\
\hline $\begin{array}{l}x_{1}=\text { No. of } \\
\text { turbines }\end{array}$ & $Y$ & $\mathrm{~N}$ & $\mathrm{Y}$ & $Y$ & $\mathrm{Y}$ & $Y$ & $\mathrm{Y}$ & Y \\
\hline $\begin{array}{l}x_{2}=\text { Distance to } \\
\text { shore }\end{array}$ & Y & Y & $\mathrm{N}$ & Y & Y & Y & Y & $Y$ \\
\hline$x_{3}=\mathrm{Cost}$ & $\mathrm{Y}$ & $\mathrm{Y}$ & $\mathrm{Y}$ & $\mathrm{N}$ & $\mathrm{Y}$ & $\mathrm{Y}$ & $\mathrm{Y}$ & $\mathrm{Y}$ \\
\hline$x_{4}=$ Area & $\mathrm{Y}$ & $\mathrm{Y}$ & $\mathrm{Y}$ & $\mathrm{Y}$ & $\mathrm{N}$ & $\mathrm{Y}$ & $\mathrm{Y}$ & $\mathrm{Y}$ \\
\hline $\begin{array}{l}y_{1}=\text { Electricity } \\
\text { production }\end{array}$ & Y & Y & Y & Y & Y & $\mathrm{N}$ & Y & Y \\
\hline$y_{2}=$ Connectivity & $\mathrm{Y}$ & $\mathrm{Y}$ & $\mathrm{Y}$ & $\mathrm{Y}$ & $\mathrm{Y}$ & $\mathrm{Y}$ & $\mathrm{N}$ & $\mathrm{Y}$ \\
\hline$y_{3}=$ Water depth & $\mathrm{Y}$ & $\mathrm{Y}$ & $\mathrm{Y}$ & $\mathrm{Y}$ & $\mathrm{Y}$ & $\mathrm{Y}$ & $\mathrm{Y}$ & $\mathrm{N}$ \\
\hline $\begin{array}{l}\text { Average CCR } \\
\text { efficiency score }\end{array}$ & 0.87 & 0.85 & 0.85 & 0.75 & 0.8 & 0.74 & 0.79 & 0.64 \\
\hline
\end{tabular}


The average efficiency score of the original model including all the inputs and output variables is higher compared to the other 7 models $(0.87)$. This is to be expected as allowing the units more dimensions by which they can gain their efficiency, normally, results in a higher efficiency score, conversely removing a measure can result in a lower efficiency score. Removing the input related to cost, in model 3 results in the lowest average efficiency (0.75) and removing the water depth output leads to the lowest efficiency (0.64). The results of the sensitivity analysis shows that all the inputs and outputs, and especially the cost and the water depth have an effect on the efficiency score of the wind farms.

\section{Conclusions}

In this study the estimated efficiency of 71 offshore wind farms across five European countries including Germany, United Kingdom, Netherlands, Belgium and Denmark has been assessed using a DEA CCR method, and the reported average CCR efficiency score of the offshore wind farms is $87 \%$. This cross European analysis is useful to understand the current state of the industry and shall provide a benchmark for future analysis as well as providing further insight on the factors affecting the efficiency of wind farms which is shown in the sensitivity analysis. Several offshore wind farms in Germany, and Denmark have been highlighted as dominating a range of wind farms across multiple North Western European countries. Further investigating of the properties of these wind farms is recommended on a case by case basis in order that the logistical and operational factors where good practice can be replicated are distinguished from non-replicable factors that are specific to those sites. Some offshore wind farms from the other nations on the other hand, do dominate a number of other wind farms across the region, but not at the level of the most highly efficient German and Danish farms. Further investigations are hence recommended into the distinct nature of German and Danish wind farms, again to assess the replicability of good practice.

The slightly higher, although not statistically significant, efficiency and high reference levels of the German wind farms is in part due to the relative input-output basis of the DEA analysis, but also has other potential underlying causes. This paper highlights one potential cause, the length and complexity of the component supply chains from the German-Danish base to the UK offshore wind farms. This applies to both the construction phases of future and the operational phase of current and future wind farms. At the time of writing, there is significant political uncertainty between the UK and the European Union that may affect future supply chains and hence the efficiency of future UK wind farms. Therefore, it is 
recommended that this aspect is monitored and mitigated as possible as political developments unfold. The general relationship between length of supply chains and efficiency of offshore wind farms is worthy of further investigation in other geographical regions, particularly where there exists a long distance between the component manufacturing base and the offshore wind farm locations. However, transferal to onshore wind farms is not possible due to the different operating conditions giving rise to some new inputs or outputs and removal of others.

The results of the DEA analysis show that the efficiency score is not evenly spread across the countries, however, the result of the statistical analysis shows that the median efficiency scores of the wind farms are not statistically different from one another and therefore wind farms show a relatively high average efficiency score across all the countries studied in this analysis.

The Offshore wind industry is an attractive and rapidly growing source of marine renewable energy and there is a need to assess the performance of this technology on a broad scale i.e. assessing as many decision making units as possible. This study offers a practical and holistic performance assessment to the offshore wind stakeholders and policy makers by including economic, environmental, technical and social inputs and outputs in the analysis.

\subsection{Future research}

In this analysis the CCR-DEA has been used, however, other DEA variants could be applied for a comparative study in which more comprehensive results could be drawn. Secondly, DEA is a descriptive analytical technique that allows decision makers to understand the relative level of efficiency of a set of units rather than providing prescriptive decision making suggestions. Whilst understanding the relative efficiency of offshore wind values is valuable, the authors also suggest that future research may focus on employing other descriptive methods, and providing recommendations on the prescriptive improvement actions to increase the efficiency of inefficient wind farms through the use of other multi-criteria decision making methods.

\section{Acknowledgments}

The authors would like to thank the reviewers for providing valuable suggestions and constructive feedback. 


\section{References}

1. WindEurope. Offshore Wind in Europe, key trends and statistics 2018 https://windeurope.org/wp-content/uploads/files/about-wind/statistics/WindEuropeAnnual-Offshore-Statistics-2018.pdf. 2019.

2. Gernaat, D.E.H.J., et al., Global long-term cost dynamics of offshore wind electricity generation. Energy, 2014. 76: p. 663-672.

3. $\mathrm{Li}, \mathrm{J}$. and $\mathrm{X} . \mathrm{Yu}$, Onshore and offshore wind energy potential assessment near Lake Erie shoreline: A spatial and temporal analysis. Energy, 2018. 147: p. 1092-1107.

4. Charnes, A., W.W. Cooper, and E. Rhodes, Measuring the efficiency of decision making units. European Journal of Operational Research, 1978. 2: p. 429-444.

5. Farrell, M.J., The measurement of productive efficiency. Journal of the Royal Statistical Society. Series A (General) 1957. 120(3): p. 253-290.

6. Liu, J.S., et al., A survey of DEA applications. Omega, 2013. 41(5): p. 893-902.

7. Zhou, P., B.W. Ang, and K.L. Poh, A survey of data envelopment analysis in energy and environmental studies. European Journal of Operational Research, 2008. 189: p. 1-18.

8. Stewart, T.J., Relationships between data envelopment analysis and multicriteria decision analysis. Journal of the Operational Research Society, 1996. 47: p. 654-665.

9. Seiford, L.M. and R.M. Thrall, Recent Developments in DEA: the Mathematical Programming Approach to Frontier Analysis. Journal of Econometrics, 1990. 46(1-2): p. 7-38.

10. Ederer, N., Evaluating capital and operating cost efficiency of offshore wind farms: A DEA approach. Renewable and Sustainable Energy Reviews, 2015. 42: p. 1034-1046.

11. Saglam, U., A two-stage data envelopment analysis model for efficiency assessment of 39 state's wind power in the United States. Energy Conversion and Management, 2017. 146: p. 52-67.

12. Wu, Y., et al., Efficiency assessment of wind farms in China using two stage data envelopment analysis. Energy Conversion and Management, 2016. 123: p. 46-55.

13. Iglesias, G., P. Castellanos, and A. Seijas, Measurement of productive efficiency with frontier methods: A case study for wind farms. Energy Economics, 2010. 32(5): p. 1199-1208. 
14. Halkos, G.E. and N.G. Tzeremes, Analyzing the Greek renewable energy sector: a data envelopment analysis approach. Renewable and sustainable energy reviews, 2012. 16(5): p. 2884-2893.

15. San Cristobal, J.R., A multi-criteria data envelopment analysis model to evaluate the efficiency of the renewable energy technologies. Renewable Energy, 2011. 36(10): p. 27422746.

16. Kim, K.T., et al., Measuring the efficiency of the investment for renewable energy in Korea using data envelopment analysis. Renewable and Sustainable Energy Reviews, 2015. 47: p. 694-702.

17. Stallard, T., R. Rothschild, and G.A. Aggidis, A comparative approach to the economic modelling of a large-scale wave power scheme. European Journal of Operational Research, 2008. 185: p. 884-898.

18. Song, M.-L., et al., Bootstrap-DEA analysis of BRICS' energy efficiency based on small sample data. Applied Energy, 2013. 112: p. 1049-1055.

19. Jebali, E., H. Essid, and N. Khraief, The analysis of energy efficiency of the Mediterranean countries: A two-stage double bootstrap DEA approach. Energy, 2017. 134: p. 991-1000.

20. Azadeh, A., A. Rahimi-Golkhandan, and M. Moghaddam, Location optimization of wind power generation-transmission systems under uncertainty using hierarchical fuzzy DEA: $A$ case study. Renewable and Sustainable Energy Reviews, 2014. 30: p. 877-885.

21. Banker, R.D., A. Charnes, and W.W. Cooper, Some models for estimating technical and scale inefficiencies in data envelopment analysis. Management Science, 1984. 30(9): p. 1078-1092.

22. Cook, W.D., K. Tone, and J. Zhu, Data envelopment analysis: Prior to choosing a model. Omega, 2014. 44: p. 1-4.

23. Vieira, M., et al., European offshore wind capital cost trends up to 2020. Energy Policy, 2019. 129: p. 1364-1371.

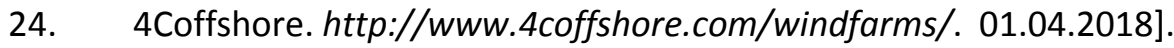

25. PowerTechnology, https://www.power-technology.com/projects.

26. Rockmann, C., S. Lagerveld, and J. Stavenuiter, Operation and Maintenance Costs of Offshore Wind Farms and Potential Multi-use Platforms in the Dutch North Sea. Aquaculture Perspective of Multi-Use Sites in the Open Ocean, ed. L.R.e. Buck B. 2017: Springer, Cham.

27. Inflation data. 2019; Available from: https://www.inflation.eu/.

28. DECC, Annual report and accounts. 2015, Department of Energy \& Climate Change

29. Coates, D.A., et al., Short-term effects of fishery exclusion in offshore wind farms on macrofaunal communities in the Belgian part of the North Sea. Fisheries Research, 2016. 179: p. 131-138.

30. Jones, D.F. and G. Wall, An extended goal programming model for site selection in the offshore wind farm sector. Annals of operations research, 2016. 245(1-2): p. 121-135.

31. Igwemezie, V., A. Mehmanparast, and A. Kolios, Current trend in offshore wind energy sector and material requirements for fatigue resistance improvement in large wind turbine support structures - A review. Renewable and Sustainable Energy Reviews, 2019. 101: p. 181-196.

32. Golany, B. and Y. Roll, An application procedure for DEA. OMEGA, 1989. 17(3): p. 237-250.

33. Arrambide, I., I. Zubia, and A. Madariaga, Critical review of offshore wind turbine energy production and site potential assessment. Electric Power Systems Research 2019. 167: p. 3974.

34. Mendenhall, W. and T. Sinchich, Statistics for engineering and the sciences. 1995, Upper Saddle River, New Jersey: Prentice-Hall, Inc.

35. Irawan, C.A., et al., A combined supply chain optimisation model for the installation phase of offshore wind projects. International Journal of Production Research, 2018. 56(3): p. 11891207. 
543

544

545

546

547

548

549

550

\section{Appendix}

\begin{tabular}{|c|c|c|c|c|c|c|c|c|}
\hline & & \multicolumn{4}{|c|}{ Inputs } & \multicolumn{3}{|c|}{ Outputs } \\
\hline & $\begin{array}{l}\text { Offshore wind } \\
\text { farms }\end{array}$ & No.turbine & $\begin{array}{l}\text { Social } \\
\text { Impact }\end{array}$ & $\begin{array}{l}\text { Are } \\
\mathrm{a} \\
\mathrm{km}^{2}\end{array}$ & $\begin{array}{l}\text { combined(millio } \\
\mathrm{n} £ / \mathrm{MW} \text { ) }\end{array}$ & $\begin{array}{l}\text { annual energy production } \\
\text { (GWh) }\end{array}$ & $\begin{array}{l}\text { Connectivit } \\
\mathrm{y}\end{array}$ & $\begin{array}{l}\text { Water } \\
\text { depth }\end{array}$ \\
\hline 1 & Scroby Sands & 30 & 5 & 4 & 3.25 & 142.4326 & 0.030186 & 5 \\
\hline 2 & North Hoyle & 30 & 4 & 10 & 3.29 & 164.8836 & 0.033063 & 8.5 \\
\hline 3 & Kentish Flats & 30 & 5 & 10 & 2.77 & 180.2663 & 0.049661 & 3.5 \\
\hline 4 & Burbo Bank & 25 & 4 & 10 & 3.52 & 212.3322 & 0.063561 & 2.5 \\
\hline 5 & $\begin{array}{l}\text { burbo bank } \\
\text { extension }\end{array}$ & 32 & 4 & 40 & 6.00 & 1166.521 & 0.04894 & 8.5 \\
\hline 6 & Beatrice & 84 & 4 & 131 & 5.95 & 1477.845 & 0.007617 & 42.5 \\
\hline 7 & $\begin{array}{l}\text { Hornsea project } \\
1\end{array}$ & 174 & 1 & 407 & 5.40 & 5289.842 & 0.006887 & 30.5 \\
\hline 8 & East Anglia 1 & 102 & 1 & 205 & 6.20 & 3005.043 & 0.010766 & 35.5 \\
\hline 9 & Dudgeon & 67 & 2 & 55 & 6.45 & 1798.595 & 0.014147 & 18 \\
\hline 10 & Rampion & 116 & 4 & 79 & 6.24 & 1966.147 & 0.029577 & 29 \\
\hline 11 & Galloper & 56 & 2 & 113 & 7.44 & 1855.832 & 0.010544 & 27 \\
\hline 12 & $\begin{array}{l}\text { Walney } \\
\text { extension }\end{array}$ & 87 & 3 & 149 & 3.58 & 1530.626 & 0.019795 & 37 \\
\hline 13 & $\begin{array}{l}\text { Walney Phase } \\
1\end{array}$ & 51 & 4 & 28 & 6.49 & 793.8238 & 0.02503 & 21 \\
\hline 14 & $\begin{array}{l}\text { Walney Phase } \\
2\end{array}$ & 51 & 3 & 45 & 7.08 & 998.4333 & 0.02106 & 27 \\
\hline 15 & Race bank & 91 & 2 & 62 & 5.54 & 2371.951 & 0.012837 & 15 \\
\hline 16 & Lincs & 75 & 5 & 41 & 6.70 & 1202.676 & 0.01215 & 12 \\
\hline 17 & London array & 175 & 3 & 122 & 6.86 & 3596.732 & 0.020775 & 11.5 \\
\hline 18 & Lynn & 27 & 5 & 10 & 3.14 & 256.0966 & 0.012524 & 9 \\
\hline 19 & Teeside & 27 & 5 & 4 & 6.20 & 281.0292 & 0.020247 & 12 \\
\hline 20 & Thanet & 100 & 4 & 35 & 4.72 & 600.8877 & 0.023836 & 18.5 \\
\hline 21 & Sheringham & 88 & 3 & 35 & 5.61 & 1125.632 & 0.017536 & 18.5 \\
\hline
\end{tabular}




\begin{tabular}{|c|c|c|c|c|c|c|c|c|}
\hline & shoal & & & & & & & \\
\hline 22 & Rhyl flats & 25 & 4 & 10 & 4.14 & 237.1265 & 0.022961 & 7.5 \\
\hline 23 & Robin Rigg & 58 & 4 & 18 & 3.77 & 348.5148 & 0.01348 & 6 \\
\hline 24 & Ormonde & 30 & 4 & 10 & 5.93 & 647.5133 & 0.025062 & 19 \\
\hline 25 & $\begin{array}{l}\text { Westermost } \\
\text { rough }\end{array}$ & 35 & 4 & 35 & 5.65 & 933.457 & 0.031868 & 17 \\
\hline 26 & $\begin{array}{l}\text { West of duddon } \\
\text { sands }\end{array}$ & 108 & 3 & 67 & 6.76 & 2114.329 & 0.029766 & 19 \\
\hline 27 & Gwynt y mor & 160 & 4 & 68 & 4.91 & 1688.189 & 0.025198 & 22.5 \\
\hline 28 & Gunfleet sands & 48 & 5 & 16 & 4.48 & 439.0244 & 0.0191 & 6.5 \\
\hline 29 & $\begin{array}{l}\text { Greater } \\
\text { Gabbard }\end{array}$ & 140 & 2 & 146 & 5.98 & 2239.777 & 0.011171 & 20.5 \\
\hline 30 & $\begin{array}{l}\text { Humber } \\
\text { gateway }\end{array}$ & 73 & 5 & 27 & 6.44 & 1029.778 & 0.023769 & 13.5 \\
\hline 31 & Barrow & 30 & 5 & 10 & 3.56 & 265.3192 & 0.038863 & 14 \\
\hline 32 & $\begin{array}{l}\text { Amrumbank } \\
\text { west }\end{array}$ & 80 & 1 & 33 & 6.51 & 1561.375 & 0.005701 & 22.5 \\
\hline 33 & Bard offshore & 80 & 1 & 59 & 10.29 & 1735.606 & 0.00429 & 40 \\
\hline 34 & Butendiek & 80 & 2 & 33 & 7.89 & 1566.17 & 0.004597 & 19.5 \\
\hline 35 & EN BW Baltic 1 & 21 & 4 & 7 & 6.22 & 134.739 & 0.014989 & 17.5 \\
\hline 36 & EN BW Baltic 2 & 80 & 2 & 30 & 6.84 & 1149.14 & 0.008387 & 31 \\
\hline 37 & Dantysk & 80 & 1 & 66 & 7.15 & 1654.155 & 0.003985 & 25 \\
\hline 38 & Global tech 1 & 80 & 1 & 42 & 6.98 & 1583.224 & 0.004443 & 39.5 \\
\hline 39 & Riffgat & 30 & 1 & 6 & 8.07 & 601.8295 & 0.005943 & 20.5 \\
\hline 40 & Sand bank & 72 & 1 & 47 & 8.06 & 1811.052 & 0.003742 & 27.5 \\
\hline 41 & $\begin{array}{l}\text { trianel windpark } \\
\text { borkum }\end{array}$ & 40 & 1 & 23 & 4.96 & 399.2861 & 0.00532 & 30 \\
\hline 42 & Arkona & 60 & 2 & 39 & 4.14 & 1055.604 & 0.00669 & 24.5 \\
\hline 43 & $\begin{array}{l}\text { borkum } \\
\text { riffgrunde } 1\end{array}$ & 78 & 1 & 36 & 6.27 & 1588.658 & 0.00562 & 26 \\
\hline 44 & $\begin{array}{l}\text { Borkum } \\
\text { Riffgrund } 2\end{array}$ & 56 & 1 & 36 & 5.76 & 2130.341 & 0.005534 & 27 \\
\hline 45 & Merkur & 66 & 1 & 39 & 5.73 & 1101.627 & 0.005476 & 30 \\
\hline 46 & Nordergrunde & 18 & 4 & 3 & 6.04 & 407.8694 & 0.010706 & 7 \\
\hline 47 & wikinger & 70 & 1 & 34 & 5.96 & 1175.707 & 0.006682 & 38 \\
\hline 48 & Veja mate & 67 & 1 & 51 & 8.33 & 2329.999 & 0.00423 & 40 \\
\hline 49 & Alpha ventus & 12 & 1 & 4 & 6.74 & 200.5886 & 0.005626 & 29 \\
\hline 50 & Nordsee One & 54 & 1 & 35 & 5.21 & 1205.254 & 0.006043 & 28.5 \\
\hline 51 & $\begin{array}{l}\text { Meerwind } \\
\text { sud/ost }\end{array}$ & 80 & 1 & 40 & 6.88 & 1561.375 & 0.006161 & 25.5 \\
\hline 52 & Belwind & 55 & 1 & 13 & 5.71 & 676.9664 & 0.010679 & 16 \\
\hline 53 & $\begin{array}{l}\text { nobelwind } \\
\text { offshore wind } \\
\text { farm }\end{array}$ & 50 & 1 & 22 & 6.24 & 730.95 & 0.010817 & 26.5 \\
\hline 54 & $\begin{array}{l}\text { North wind } \\
\text { offshore wind } \\
\text { farm }\end{array}$ & 72 & 2 & 14 & 7.53 & 1392.785 & 0.007758 & 19 \\
\hline 55 & $\begin{array}{l}\text { Thornton Bank } \\
1\end{array}$ & 6 & 3 & 2 & 7.89 & 146.8953 & 0.012967 & 20 \\
\hline 56 & Thonton bank 2 & 30 & 3 & 12 & 4.56 & 734.4764 & 0.012997 & 13 \\
\hline 57 & $\begin{array}{l}\text { Thornton Bank } \\
3\end{array}$ & 18 & 3 & 7 & 9.88 & 333.3458 & 0.012885 & 16 \\
\hline 58 & Rentel & 42 & 2 & 23 & 4.53 & 738.9227 & 0.012399 & 29 \\
\hline 59 & Norther & 44 & 3 & 38 & 4.52 & 774.1095 & 0.013955 & 19.5 \\
\hline 60 & $\begin{array}{l}\text { Egmond aan } \\
\text { Zee }\end{array}$ & 36 & 4 & 24 & 5.08 & 278.2169 & 0.042655 & 16.5 \\
\hline 61 & Eneco & 43 & 3 & 16 & 4.83 & 400.1407 & 0.02845 & 20 \\
\hline
\end{tabular}




\begin{tabular}{|c|c|c|c|c|c|c|c|c|}
\hline & Luchterduinen & & & & & & & \\
\hline 62 & Gemini & 150 & 1 & 70 & 7.54 & 3640.003 & 0.006981 & 33 \\
\hline 63 & Prinses Amalia & 60 & 3 & 17 & 11.44 & 558.3359 & 0.027681 & 21.5 \\
\hline 64 & $\begin{array}{l}\text { Westermeerwin } \\
\text { d }\end{array}$ & 48 & 3 & 16 & 3.63 & 414 & 0.017857 & 5 \\
\hline 65 & Anholt & 111 & 3 & 116 & 5.00 & 1589.021 & 0.012744 & 15.5 \\
\hline 66 & Middlegrunden & 20 & 1 & 10 & 10.63 & 48.12018 & 0.154921 & 4.5 \\
\hline 67 & Rodsand 2 & 90 & 1 & 34 & 3.60 & 577.453 & 0.007085 & 9 \\
\hline 68 & Horns Rev 3 & 49 & 3 & 144 & 3.47 & 977.6694 & 0.006063 & 15.5 \\
\hline 69 & Horns Rev 1 & 80 & 1 & 21 & 3.16 & 379.8203 & 0.006031 & 8.5 \\
\hline 70 & Nysted & 72 & 5 & 26 & 5.02 & 359.1439 & 0.007334 & 7.5 \\
\hline 71 & Horns Rev2 & 91 & 1 & 33 & 3.43 & 583.8692 & 0.005709 & 13 \\
\hline
\end{tabular}

551 